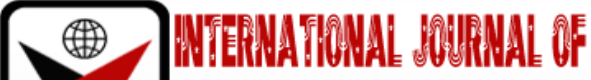

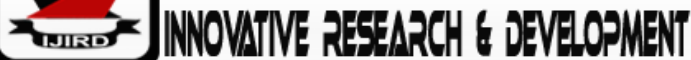

ISSN 2278-0211 (Online)

\section{Strategies That Can Be Used to Improve Effectiveness of Sexual Health Education Programmes in Bulawayo's Mzilikazi District, Zimbabwe}

Sibusisiwe Ncube
Part time Lecturer, Department of Higher Education, Zimbabwe Open University, Zimbabwe
Onias Mafa
Professor, Department of Higher Degrees, Zimbabwe Open University, Zimbabwe

\begin{abstract}
:
Early teenage pregnancies in the $21^{\text {st }}$ century have suddenly become a major public health issue which has a potential to erode all the gains achieved in trying to empower the girl child for self sustainance.The study through 'health risk' sensitive lenses evaluated thestrategies used in the teaching of Sexual Health Education Programmes in reducing early teenage pregnancies in Zimbabwe.The study was conducted in three selected schools in Mzilikazi District in Bulawayo metropolitan province.The Ecology Theory informed this research. The theory was selected based on four key variables relevant to teenage physical growth and mental development. The variables are interaction and participation, empowerment and adaptation to the environment in which they live. The study adopted a case study approach and employed a qualitative methodology of enquiry based on an interpretivist paradigm. The idea was to build a holistic picture of lived experiences of research participants. Convenience sampling technique was adopted in the selection of the research participants owing to the sensitivity of the subject matter under discussion. The sample size was 70 and all participants freely accepted the invitation without being induced or being enticed to partake in the study. Questionnaires, Focus Group Discussions (FGD) and Interviews were employed as data generating techniques in order to ensure trustworthiness of data. Captured audio/voice responses were transcribed and later slotted into emerging themes. Data were analysed and synthesised through the use of Word Query. The study established that, training of teachers on the teaching of Sexual Health Education can result in the effective teaching of Sexual Health Education which may culminate in a reduction of teenage pregnancies, providing adequate resources to help in the teaching of the subject, allocation of enough time for the subject in the school curriculum and improving teaching methods are best strategies in the teaching of Sexual Health Education. The study recommends that the Ministry of Primary and Secondary Education, through the Curriculum Development Unit, calls for teachers' contribution in the research, development and diffusion of Sexual Health Education information to improve ownership of the programme and to decentralise it.
\end{abstract}

Keywords: Sexual health education, teenage pregnancies

\section{Introduction}

The observed persistence of teenage pregnancies and school dropouts has prompted an investigation into strategies that can be used in the delivery of sexual health education programmes in schools.Many teenagers are sexually active and therefore are at risk of getting infected by HIV and having unwanted pregnancies (Zaba, Pisani, Slaymaker, Boerma 2004). Although there are variations according to regions, Africa as a continent is characterized by high birth and death rates. According to estimates there are 38 babies born and 14 people dying per 1,000 people leading to an increase in population rate to up to $2.4 \%$. The number of children born per 1,000 people ranged from as low as 16 in Mauritius to 51 in Malawi while the number of people dying per 1,000 people ranged from 4 in Algeria and Libya to 29 in Sierra Leone. An increase in population was recorded in Niger and Comoros (3.5\%) while the lowest was recorded in Botswana (0.1\%). (Population Reference Bureau: 2004 World population Data Sheet).Debates have ensued following the adoption of Sexual Health Education in schools, high birth and death rates have prompted various studies on the subject (Kirby 2001; 2008). Since its adoption, there has been a major transformation on sexuality education in schools, as initial studies looked on whether to teach sexuality education or not, while recent studies have shifted focus to the type of sexuality education best for learners.

\section{Statement of the Problem}

The observed persistence of teenage pregnancies and school dropouts has prompted an investigation into strategies that can be used in the delivery of Sexual Health Education programmes in schools. 


\section{Research Questions}

This research study focuses on the questions:

- What strategies can be used to improve effectiveness of Sexual Health Education Programmes?

- What are the challenges associated with the implementation of sexual education programmes?

- How can the challenges (if any) can be mitigated?

\section{Review of Related Literature}

\subsection{Theoretical Framework}

\subsubsection{The Ecological Theory}

This theoretical framework is based on work done by Svanemyr, Amin, Robles and Greene (2014) who suggests an ecological approach which is grounded on creating a safer and encouraging space. This theory involves a set of correlated factors such as the legal, political, social, and cultural, among others that affect the capability of infantile individuals to live healthier lives while accessing relevant and necessary services, information, and products. Developing such a conducive environment demands effective handling of a wide range of structural elements beyond the individual that is vital in moulding successful health education achievements and other aspects of health and development (Svanemyr, Amin, Robles,and Greene 2015). The ecological theory thus is broadly implemented tofully understand the determinants of a broad range of health behaviours together with results from its four guiding principles. To start with, it recognises the compound roles on health behaviours and results, including elements that guide the intrapersonal, interpersonal, organisational, community, and public policy stages. Secondly, it stipulates that such influences interact across the above mentioned varrying stages. Thirdly, it needs a focus on particular health behaviours and outcomes, understanding the factors that are most likely to play bigger roles in the specific behaviour or outcome at each level of the framework. Finally, Svanemyr et al. (2014) note that the framework suggests that intervention measures that focus on the factors at multiple levels are most likely to be effective than those that focus on only one level as depicted in Figure 4.1. below.

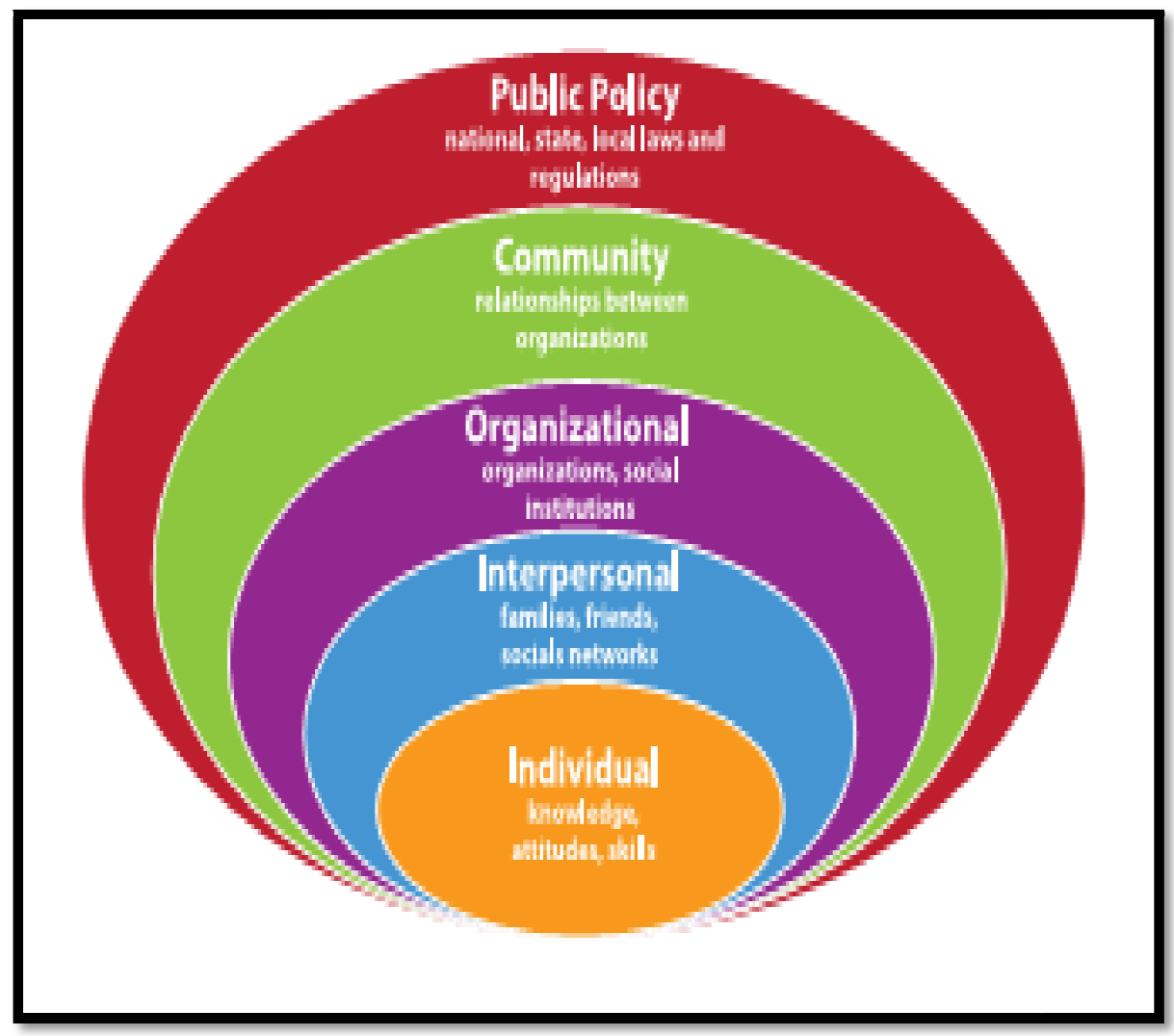

Figure 1: The Ecological Model

\subsubsection{Adopted from Svanemyr, Amin, Robles, and Greene (2015)}

The above Figure 1 gives retrospection to a comparative summation on approaches in research by researchers like Kirby (1995) and King (1999) whilst studying Sexual Health behaviours of learners in American schools. The theoretical framework identifies strategies to improve Sexual Health Education programmes aimed at four levels that is :individual, relationship, community, and societal levels. In identifying strategies, the framework also reflects on problems that are at the disposal of organisations when putting these programmess into practice and also perceptions among the youth about Sexual Health Education programmes. 


\subsection{Strategies That Can Be Used to Improve The Effectiveness of Sexual Health Education Programmes}

The National Sexuality Education Standards (NSES, 2012) proffers strategies based on a strategic and holistic approach to sexual health care which includes family and community participation, school health services, a healthy school environment and healthy education and sexuality education. Once the above stakeholders are proactive, it becomes easier for policies or laws on Sexual Health Education to be enacted and implemented effectively.Sorace (2013) describes a policy, in general, as a legislation, regulation, procedure or administrative action to advance the desired result. Relative to sexual health, the desired results are teenagers who are equipped with the accurate information, education, and skills to make healthy, responsible decisions as well as access to sexual and reproductive health care services. The NSES (2012) therefore suggests that effective sexuality education programmes should consist of the following characteristics imbeded in it:

- Focuses on specific behavioural outcomes;

- Considers personal values and group norms that encourage health-enhancing behaviours;

- Looks at improving individual's perceptions of risk and dangers of engaging in certain health risks

- $\quad$ Practises as well as reinforcing protective factors;

- Looks into the social pressures and influences;

- Enacts personal and social competence;

- Distributes functional knowledge that is critical, correct and directly influences health-promoting practices and behaviours;

- Uses measures designed to personalise information and engage learners;

- Integrates learning strategies, teaching practices and facilities that are culturally inclusive (an effective curriculum has materials contains unbiased information and includes information, activities, and examples that are inclusive of different cultures and societies);

- $\quad$ Allocates adequate time for teaching and learning;

- Enables the environment and spaces that allow reinforcement of skills and positive health behaviours;

- Allows opportunities to network with other influential persons;

- Incorporates teacher information and plan for professional development and training to enhance the effectiveness of quality teaching and learning, and

- $\quad$ Teaching by educators who are experts in sexuality education is critical for learner achievement.

\subsection{Equal Opportunities for Participation Recquired}

In their analysis of findings from the Social science research from the MEMA Kwa Vijana team Jewkes (2010) and Rijsdijk (2013) criticises the school-based strategies which they argued was being enacted in a context of massive gender and status power variations between the educators and the learners. The authors argue that such settings enabled the opportunities for rape, bullying, economic exploitation, and beating of learners, thus severely undermining positive messages from the initiative. The authors also note that wide range community engagement with the initiative was very limited since programme was being delivered in schools, it then had to be tailor made to accommodate the limitations of the classroom as a result. Therefore, the curriculum was delivered in 12 lessons per year of 40 minutes each, for a maximum of 3 years. However, Kirby (2001), (2007), (2011), Mukoma (2004), Giami, Ohlrichs, Quilliam, Wellings, Pacey, Wylie, (2006), UNESCO (2009), Jewkes (2010) view schools as institutions best suitable for sex education and as a pragmatic response to a social need and argue that while the context may be less than ideal, it is the best available option.

\subsection{Ensure Teacher Training on Sexual Health Education}

Lack of teacher training in schools has hampered Sexual Health EducationProgrammes (Mukoma(2009) and Jewkes 2010). The authors note that teachers in most cases received short capacity building training in delivering the intevention strategy, and since they were not knowlegeable with participatory methods, there were also a number of omissions within the curriculum like the practical buying of condoms from shops, and the use of condoms. On the other hand, besides short training, Giami (2006) also notes that the educators' own personal backgrounds were inevitably associated with their teaching methods in a number of subtle and observable ways. The same can be said for guardians, educators and other people involved in Sexual Health Education who have morals and values on these highly sensitive issues and they influence how teachers mediate Sexual Health Education curriculum within classroom set up, (Giami, 2006; Mukoma et al. 2009, Jewkes, 2010). Mukoma et al (2009) further hints that it is very important that teachers are made aware of their own value structures and how these are associated with what and how they deliver education on sexuality. This is mostly important when the educators themselves are involved in teaching comprehensive Sexual Health Education programmes. When their own personal backgrounds contradict with the values and rights promoted in comprehensive Sexual Health Education lessons. Mukoma et al (2009) and Giami et al (2006) concur that for the majority of educators, talking about sexuality generates a lot of stress, nervousness, shyness and discomfort in a society where discussing sexual matters is perceived as a taboo. This is more so in an African context, some educators have indicated a lot of concern that by discussing or teaching about sex they might inadvertently stimulate the curiosity of their learners about sex and even encourage them to experiment with sexuality (Fransis, 2009).

Some teachers are not comfortable in facilitating lessons on sex to teenagers or are apprehensive about negative parental responses to an extent of even possible accusations (Jewkes, 2009; 2010). Such sentiments and distress on the part of teachers might influence similar attitudes amongst the learners during sexuality education lessons, leading to little or no participation and room for discussion on the topic at hand. Goldman (2008) thus concluded that some teachers 
confine themselves to teaching abstinence-only lessons rather than those which intend to incorporate emotions and bodily feelings of desire and attraction. Such concerns indicate the significance of adequately providing development on-the-job training for the teachers so that they are more equipped to effectively teach concepts related to sexuality.

\subsection{Promotion of the Participatory Approach to Sexual Health EducationBe Prioritised}

Whilst assessing Sexual Health Education programmes in Sub-Saharan countries, Pattman and Chege (2003) notes that the needs of boys and girls in sex education classes can vary and are largely influenced by cultural and social backgrounds. The same authors also found that girls tended to be usually quieter during SexualEducation classes and their educators usually did not make enough efforts to engage them in sexual discussions. Great attention must be paid to such situations and if noted, should be picked up and looked into at their commencement. Detecting such anomalies helps to ensure both girls and boys participate freely in Sexual Health Education programmes in schools. There is need to change gender norms and get rid of gender violence within and outside schools by educating both girls and boys ( men and women) the needed critical thinking skills to challenge the subordination of women and girls in societies.

Jewkes (2010) attributes the success of the Stepping Stones programme in Southern African countries to the participatory nature of the programme and its gender-transformative intervention nature that put heavy emphasis on skills development. The author found out that the programme educated and emphasised thinking skills as well as communication skills, rather than focusing on knowledge only. Giami et al (2006) noted that NGOs have been called upon to offer help to the Ministries of Education in order to develop and initiate reproductive and Sexual Health Education programmes in most nations. Their participation mostly involves teacher development and training, learner orientations and seminars as well as youth camps and production of materials.

\subsection{Improved Legislation}

In countries like America, advocating and raising awareness of increasing levels of STIs and HIV/AIDS brought the first National Strategy for Sexual Health and HIV (DH, 2001). In this regard, the association between sexual health, social exclusion, and poverty were noted. This was alongside the unequal impact of HIV on gay men and some other minority and marginalised ethnic groups. This appeared to indicate a determined intention by the national government, for the first time, to improve the standards for sexual health. In developing countries, (South Africa, Zambia, and Malawi) various pieces of legislation have been promulgated to ensure that Sexual Health Educationis implemented in schools.

In South Africa, the education ministry approved an instrument on Health Education HIV/AIDS Emergency: Guidelines for Educators (Department of Education, 2000). It intends to consider teacher resistance to teach about safe sex, encouraging them to be more realistic about teenage sexuality education. Challenges emerge as the policies are subject to interpretation, for example, the policy on Sexual Health Education has a section which instructs that it should be shown in a scientific but simple way (Department of Education, 1999). In this way, little guidance will be offered to teachers with regards to what they teach and on matters of pedagogy. Scholars like Roth (2005) bemoan lack of coherence as such kind of an approach by government exerts pressure on teachers as to what to teach and the approaches needed in a school environment. The author notes that in most schools in Africa, teachers lack consistency of development training and are from a different range of fields which do not always effectively equip them with adequate skills to deliver quality Sexual Education confidently and effectively.

From our didatic perspective it becomes clear that with such policies in place, teachers feel they now have a lever for substantial change, one that would allocate the resources and really make a huge difference in improving Sexual Health Education in the African schools. There are still some gaps because this strategy has been seen to be very clinically focused and not giving adequate credence to the prevention and health promotion work that is needed to underpin any change.

\subsection{Effective Leadership}

According to the National Sexuality Education Standards (2012) quality leadership that crafts strategies and improves Sexual Health Education services based on all stakeholders' views are needed in order for teenagers to improve their Sexual Health Education. This calls for a paradigm shift. Schools and society should move a step further since it is not just about good teaching that shape behaviour, even though this is a critical element. Such services should be distributed to the teenagers and teachers when they need them at any time and in a way that does not discourage and demotivate them. Nettleton (2006) suggeststhat there is a need for relevant systems to be in place, systems that respond to teenages' needs, and the whole individual within the context of their livelihoods within society, maintaining dignity throughout. The partnership between learner, teacher and learning institutions is what is required for successful SHE programmes. This means a fundamental shift in thinking is required though it may not be instantaneous.

\section{Research Methodology and Design}

The study adopted a case study method and employed a qualitative methodology of enquiry based on an interpretivist approach. The idea was to build a holistic picture of lived experiences of selected research participants. The study was inductive in nature so as to incorporate various views and perceptions of stakeholders on the issue of Sexual Health Education and its relevance to the reduction of early teenage pregnancies in Mzilikazi District. This is because the research was underpinned by a phenomenological slant which is a science whose principle is to describe teaching health education in teenagers and its contribution to reduction of teenage pregnancies as a lived experience (Creswell, 2013). We felt that by using an Interpretivist philosophy, We would be able to capture participants' views. Thus We chose to interview stakeholders who include; Education Officers, School Heads Teachers and Parents. We also coducted focus group discussions with form one to six learners.Interpretivists assert that reality can be deeply understood through subjective 
(Yin, 2006). Saunders, Lewis, and Thornhill (2009) buttresses that the study of phenomena in their natural environment is critical to the interpretivist philosophy. Interview proceedings were recorded in verbatim,transcribed and sent back to participants,before data analysis usingthe thematic content approach.

\section{Presentation of Results}

Strategies that can be adopted to improve Sexual Health Education Programmes in Mzilikazi District Schools.

Participants were asked challenges associated the teaching of Sexual Health Programmes with the ultimate goal being to reduce transmission of STIs and pregnancies among teenagers.

\subsection{There Is Need for Teacher Commitment and Training on How to Deliver teenage Sexual Health Lessons in Schools} Most participants reiterated the need for teacher commitment and capacitation.

- $\operatorname{Tr} 1$ sch 1: There is a need for the government to make it mandatory for Teacher's training colleges to train teachers on comprehensive sexual health education. It has to be mandatory because we cannot continue scratching the surface yet we are sailing in deep waters. Teachers in schools must be compelled to fully embrace comprehensive teenage sexual health education, this way all issues can be discussed openly.

- The above view was corroborated by $\operatorname{Tr} 1$ sch 3 who pointed out that: We have to move with time, teenagers today need us to engage them fulltime, gone are the days when we would talk of teenage sexual health education confined to abstinence only. This does not work, let's engage them, let them be informed and let them make decisions from an informed position.

- It seems participants are calling for the government through the Ministry of Primary and Secondary Education to make it mandatory for teachers to be trained by government or established academic institutions on teenage sexual health education. The government can then ride on the gender-based violence which has recently been launched in the Zimbabwean school curriculum.

- Another issue raised by participants is the need to have a harmonized approach to teenage Sexual Health Education. This was raised in light of different approaches being used by teachers when engaging teenagers on Sexual Health EducationProgrammes within schools in Mzilikazi District. This idea reverberated in focus group discussions as indicated below.

- FG1P1: Sexual Health Education is the gateway for teenagers' future; Zimbabwe must have a comprehensive policy to guide teachers on how they should engage teenagers in schools for good teenage upbringing. As it stands each teacher seems to be selecting his or her suitable way of engaging teenagers in classes hence there is lack of consistency. Teenage Sexual Health Education should be a module or syllabus on its own rather than it being embedded in other subjects like combined science, biology.

- FG2P3: Zimbabwe needs to adopt a position on which one type of Sexual Health Education is best suited to the current generation. We must move with time; I suggest that schools should adopt the comprehensive Sexual Health Education such that all issues are discussed openly and genuine solutions to today's problems are explored and found.

- From the responses captured above, participants felt that schools were not using a uniform approach in engaging teenagers on Sexual Health Education in Mzilikazi District. Each teacher had his or her own way of engaging learners in class. Participants were advocating for the adoption of a comprehensive teenage Sexual Health Education policy for schools. This way the government would be able to direct all schools to engage teenagers on comprehensive Sexual Health Education in schools.

- Literature recognises the compound roles on health behaviours and results, including elements that guide the intrapersonal, interpersonal, organisational, community, and public policy stages.It has been evident that schools have been trying to adopt a coprehensive approach in the teaching of Sexual Health Programmes as a way of bringing solutions to the problems of unwanted pregnancies.However there was evidence of poor results.

\subsection{Need for the Engagement of Stakeholders in Formulating a National Strategy for Sexual Health Education}

The call for engaging all stakeholders in moulding teenage behaviour was raised by participants during the course of the study with some participants calling for the need to inculcate good behaviour amongst teenagers through good role models. This can start from a class, school, and District and Provincial levels. Universities have Miss University for each institution and one of the qualifications for role modelling is that one must be single and without a child. This way, teenagers (the girl child) will strive to remain single, without children in order to qualify.

Captured below are some of the responses:

- $\operatorname{Tr} 3$ sch 1: The school environment alone cannot mould a child's behaviour for children behave differently at school and at home. There is need for school authorities and parents to monitor children for any change in behaviour so as to realign them at an early stage.

- H.t sch 1: It takes a community to raise a child, for schools to engage teenagers without the full support of their parents, is a mere waste of time. Practice should begin at home so parents and members of the community should take the leading role in moulding teenagers.

- P 7: A child is for the nation and it takes a number of tributaries to flood a river. Teenagers should be engaged on Sexual Health Education both at school and at home. We need to be open with our children.

- Emerging from the above sentiments are issues relating to how various parties can be called into action to the girl child from early teenage pregnancies. Of importance is the need to prop up guidance not only from the school environment but from homes as well. However, not everyone can engage teenagers in Sexual Health Education as 
people from troubled families, marred reputation or bad character cannot be expected to positively impact on positive teenage behaviour.

- The ecological theory highlights that there is a need to focus on particular health behaviours and outcomes, understanding the factors that are most likely to play bigger roles in the specific behaviour or outcome at each level of children's growth hence the need for guidance at school as well as home to so as to impact a positive behaviour amongst teenagers.

\subsection{Calling for an All Stakeholder Consultative Approach to Deliberate on the Issue for Possible Policy Formulation and Refinement}

Participants indicated that the issue of teenage pregnancies should no longer be side lined to be discussed in corridors. Communities should utilize every opportunity at any gathering to speak out their experiences, good or bad. This way, community leaders would get an opportunity to learn and understand teenage needs since the world is dynamic, on the same token, teenagers would learn from what has befallen their peers hence take proactive steps to withdraw from the dangerous precipice hence withhold from plunging headlong. Open discussions on the matter in a nutshell would help enlighten parents and guardians on new developments on the social frontiers hence closing the generation gap.

One of the participants had this to say:

- $\quad$ P 3: I have to be open for others to learn from my mistakes, I completely lost the battle, each time I would shower my son with presents, I would give him my personal car to drive to school only to learn that he was not even attending lessons at a local university but was busy clubbing.

It could be possible that parents, out of love for their children are giving them too much freedom ultimately losing control of the day to day activities of their children. Nettleton (2006) emphasized the need for the crafting of systems that ensure teenagers freedom but with dignity being preserved throughout. In the school environment it would mean, the partnership between learner, teacher and leading institutions is what is required for successful Sexual Health Education Programmes.

The call for opening up by this parent resonates well with the reinforcement of socially learnt behaviour in the concept of Social Learning Theory. The theory has been seen to have been borrowed from Behaviourism. Kirby (1997) hints the advantage of using peer educators in projects aimed at teenagers as a great deal of time they spent socializing with their own peers. This way, the environment for consistent reinforcement of patterns of behaviour occurs. An effective communication reinforced through an ongoing interaction and is likely to be far more effective than a one-off talk or lesson. However, Perry and sieving (1993) notes that fore successful reinforcement to be attained, there is crucial need for the peer educators to have ongoing interactions with those groups which are targeted which is contrary to what was proposed by participants in this study.

The message being sent is that, any member of the community in Mzilikazi District should hear and learn from what has befallen their neighbours not on the basis that they have teenagers who are also troublesome but just to awaken community members on possibilities and realities of the world. This way community members will be in a position to watch their neighbour's back, that is being in a position to anticipate and distinguish bad from good behaviour amongst teenagers in the community. Doing so will help isolate bad mannered teenagers in the community hence save the innocent ones? What has emerged in real life situations is that most peer education programmes have tended to be one-off sessions and do not reach the broad spectrum of audiences.

\section{Conclusions}

- The subject lacks teaching and learning material and facilities and heavily relies on donated education material from NGOs and lack of commitment amongst teachers has also negatively affected quality teaching and learning processes.

- There is lack of stakeholders in moulding teenage behaviour.

- Some teachers and learners have never accessed the syllabus as it is not always available in the schools leaving teachers guessing on what and how to teach the subject.

- The schools administrators lack autonomy/work discretion to purchase the requirements to be used in their schools as fees structures and budgets control are centralized.

- Schools suffer from ineffective leadership and poor supervisory practices and lack of commitment by school leadership. The school administrators did not play their roles as advocates and are failing to display team leadership traits on teenage health education.

- Need for stakeholder involvement in the formulation of policies.

After an evaluation was done, results showed that Sexual Health Programmes are not effective in reducing teenage pregnancies as seen by the rising trends shown over years of teenagers continuously dropping out of school because of pregnancies. Programmes have been carried out in schools but there is need to change the teaching methods, improve on teacher training and provide adequate resources so as to enhance a reduction in the number of teenagers getting pregnant.

\section{Recommendations}

- There is need for in-service workshops which can be used as platform for equipping teachers with relevant skills that address teenage health problems.

- Since there is a resource shortage of learning material like textbooks, partnering with Non-Governmental Organizations in the education sector on teenage health Sexual Health Education can be the most viable option available. 
- $\quad$ There is need for the Zimbabwean government to craft a teenage Sexual Health Education policy that addresses adolescents' challenges once a policy is in place mechanisms to ensure it is followed and monitored fall into place.

- Teenagers can also be engaged through media-based education, especially television and radio which are recognized as more informative and respected channels by communities. Radios and televisions can be important sources of information about sexuality, particularly for young people. More so, in a generation when sexuality and sexual ill-health are often shrouded in secrecy and shame, which can discourage communication, encourage stigma and prevent people from accessing the needed help or information. The media should be used in assisting with and encouraging discussion of these matters by handling them as every days' health challenges that affect everyone at a particular phase in their livelihoods. The media must be taken full advantage of in raising awareness and breaking the silence on sensitive or hidden problems, such as teenage sexual and drug abuse.

- $\quad$ Selected public media platforms can be complimented by outreach programmes targeted at youths especially vulnerable groups, adolescents in schools, those who do not attend school and street children

- Opening up of telephone hotlines can be a complementary approach to teenage Sexual Health Education since it can be used as a platform for providing sexual health-related information in a safe and confidential manner.

\section{References}

i. Bandura, A. (1977). Social Learning Theory. Englewood Cliffs, NJ: Prentice Hall.

ii. Berg, B. L. (2007). Qualitative research methods for social sciences. London: Pearson.

iii. Creswell, J. W. (2013). Qualitative inquiry and research design: Choosing among five approaches (3 ${ }^{\text {rd }}$ ed.). Thousand Oaks, CA: Sage.

iv. Creswell, J. W. (2014). Research Design: Qualitative, Quantitative, and Mixed Methods Approaches. (3 ${ }^{\text {rd }}$ Ed.). Thousand Okas, CA: Sage.

v. Denscombe, M. (2007). The Good Research Guide for small-scale social research projects.3rd ed. London: Open University Press.

vi. Denscombe, Martyn (2008). Communities of Practice A Research Paradigm for the Mixed Methods Approach. Journal of Mixed Methods Research 2 (3): 270-283.

vii. Giami, A., Ohlrichs, Y., Quilliam, S., Wellings, K., Pacey, S., Wylie, K.R., (2006). Sex education in schools is insufficient to support adolescents in the 21st century. Sexual \& Relationship Therapy 21 (4), 485-490.

viii. Goldstein, R (2017). Sexual Health Education: A Comparison between Denmark and The United States, University: University of Copenhagen.

ix. Kirby D, Obasi A, Lans B.A (2006) The effectiveness of sex education and HIV education intervention in schools in developing countries inRoss D.A, Dick B, Fergurson J. Editors 103-150 Preventing HIV/AIDS in young people a systematic review of evidence from developing countries.

x. Kirby D. (2007). Emerging Answers. Washington, DC: National Campaign to Prevent Teen Pregnancy, 2007.18. Office of Adolescent Health. 'Evidence-Based Programmes (31 Programmes). Accessed March 5, 2018, from http://www.hhs.gov/ash/oah/oah-initiatives/teen_pregnancy/db/programmes.html, Accessed 06/06 /2018

xi. Klepp K, Fisher AJ, Kaaya SF, Lie GT. (2008) Ethical dilemmas in adolescent reproductive health promotion, Promoting adolescent sexual and reproductive health in East and South Africa. Cape Town, South Africa: HSRC Press; pp. 76-95.

xii. Ministry of Education, Sport, Arts and Culture, (2012) Life Skills, Sexuality, HIV and AIDS Education Strategic Plan, 2012-2015, Harare, Zimbabwe: Ministry of Education, Sport, Arts and Culture.

xiii. Ministry of Education, Sport, Arts and Culture, (2012) Ministry of Health and Child Welfare, National Adolescent Sexual and Reproductive Health Strategy, 2010-2015, Harare, Zimbabwe: United Nations Population Fund (UNFPA), UNICEF and WHO

xiv. Ministry of Health and Child Welfare (2009), National Adolescent Sexual and Reproductive Health Strategy, 20102015, Harare, Zimbabwe: United Nations Population Fund (UNFPA),

xv. Mukoma, W. (2001). Rethinking School-Based HIVIAIDS interventions in South Africa. South African Journal of Child and Adolescent Mental Health, 13(1):55-62.

xvi. Pattman, R., Chege, F., (2003). "Dear diary, I saw an angel, she looked like heaven on earth": sex talk and sex education. African Journal of AIDS Research 2 (2), 103-112.

xvii. SAfAIDS, (2011). Young People's Sexual and Reproductive Health and Rights Issues in Zimbabwe: Summary of Findings from SAfAIDS Baseline Survey in Five Provinces. Zimbabwe: SAfAIDS Regional Office

xviii. Saunders, M., Lewis, P and Thornhill, A. (2013) Research methods for business learners, 5th Ed., Harlow, Pearson Education

xix. Saunders, M., Lewis, P. and Thornhill, A. (2012) 'Research Methods for Business Learners' 6 ${ }^{\text {th }}$ edition, Pearson Education Limited

xx. Saunders, M., Lewis, P., and Thornhill, A. (2009). Research Methods for learners. Harlow: Prentice Hall.

xxi. Saunders, M., Thornhill, A. and Lewis, P. (2016). Research methods for business learners. $7^{\text {th }}$ Edition. London: Pearson Education.

xxii. Sorace, D. (2013). Addressing Sexual health in Schools policy Considerations; Advocates for Youth Spring.

xxiii. Svanemyr, J., Amin, A., Robles, O.J. and Greene, M.E. (2015). Creating an enabling Environment for adolescent sexual and reproductive health: a framework and promising approaches. Journal of Adolescent Health, 56(1), pp.S7-S14 
xxiv. Vanwesenbeeck, I., Westeneng, J., de Boer, T., Reinders, J. and van Zorge, R., (2016). Lessons learned from a decade of implementing Comprehensive Sexuality Education in resource-poor settings: The World Starts with Me. Sexual Health Education, 16(5), pp.471-486.

xxv. Vanwesenbeeck, I., Westenenga, J., Thilly de Boer, Jo Reinders, J and Ruth van Zorge (2016). Lessons learned from a decade of implementing Comprehensive Sexuality Education in resource-poor settings: The World Starts with Me, Sex Education, 2016 VOL. 16, NO. 5, 471-486 http://dx.doi.org/10.1080/14681811.2015.1111203

xxvi. Walcott, C., Chenneville, T., and Tarquini, S. (2011). A relationship between recall of sex education and college learners' sexual attitudes and behaviour. Psychology in the Schools, 48, 828-842.

xxvii. Wanje, G., Masese, L., Avuvika, E., Baghazal, A., Omoni, G. and McClelland, R.S. (2017). Parents' and teachers' views on Sexual Health Education and screening for sexually transmitted infections among in-school adolescent girls in Kenya: a qualitative study. Reproductive health, 14(1), p.95.

xxviii. WHO Health Report (2013). Skills for Health Skills-based health education including life Skills: An important component of a Child-Friendly/Health-Promoting

School,http://www.who.int/school_youth_health/media/en/sch_skills4health_03.pdf

xxix. World Health Organisation (1978) Primary Health Care: Report, on the Conference of Primary Health Care. WHO, Geneva. World Health Organisation (1986) Ottawa Charter for Health Promotion. WHO, Geneva

xxx. ZIMSTAT and ICF International (2012). Zimbabwe Demographic and Health Survey 2010-11.

xxxi. Zaba B, Pisani E, Slaymaker E, Boerma JT. Age at first sex: understanding recent trends in African demographic surveys. Sex Transm Infect. 2004;80(Suppl 2):ii28-35. 